\title{
Recent advances in compatibilization strategies of wood-polymer composites by isocyanates
}

\author{
Aleksander Hejna ${ }^{1}$ (D) - Marta Przybysz-Romatowska ${ }^{1} \cdot$ Paulina Kosmela ${ }^{1}$. \\ Łukasz Zedler $^{1} \cdot$ Jerzy Korol $^{2} \cdot$ Krzysztof Formela $^{1}$
}

Received: 22 December 2019 / Published online: 15 July 2020

(c) The Author(s) 2020

\begin{abstract}
Wood-polymer composites technologies are gaining more and more attention in the scientific community, positively affecting the increase in their industrial applications, for example, automotive, building, 3D printing, etc. Many research works are focused on the improvement in matrix-lignocellulosic filler interactions to produce highly filled composites with satisfying performance properties. In this field of research, using isocyanates due to their versatile structure and functionality seems to be a very promising approach. This paper aims at reporting on recent advances in compatibilization strategies of wood-polymer composites by isocyanates. Particular attention is focused on the correlation between isocyanate structure, as well as modification conditions on the matrix-lignocellulosic filler interactions and their impact on the structure-property relationships of wood-polymer composites. Furthermore, limitations and future research trends related to applications of isocyanate to woodpolymer composites technologies are also discussed.
\end{abstract}

\footnotetext{
Aleksander Hejna

aleksander.hejna@pg.gda.pl

Marta Przybysz-Romatowska

martaprzy5@gmail.com

Paulina Kosmela

paulina.kosmela@gmail.com

Łukasz Zedler

zedler92@gmail.com

Jerzy Korol

jkorol@gig.eu

Krzysztof Formela

kformela.ktp@gmail.com
}

1 Department of Polymer Technology, Chemical Faculty, Gdańsk University of Technology, G.

Narutowicza Str. 11/12, 80-233 Gdańsk, Poland

2 Department of Material Engineering, Central Mining Institute, Pl. Gwarków 1,

40-166 Katowice, Poland 


\section{Abbreviations}

CNCs Cellulose nanocrystals

CTDIC Urethane derivative of cardanol

CTMP Chemithermomechanical pulp

DABCO 1,4-Diazabicyclo[2.2.2] octane

DBTDL Dibutyltin dilaurate

DCP Dicumyl peroxide

DMA Dynamic mechanical analysis

DMSO Dimethyl sulfoxide

DSC Differential scanning calorimetry

FTIR Fourier transform infrared spectroscopy

HDI Hexamethylene diisocyanate

HDPE High-density polyethylene

HMDI 4,4'-Methylenebis(cyclohexyl isocyanate)

IPDI Isophorone diisocyanate

IS Isocyanate silane

LDI Lysine diisocyanate

LDPE Low-density polyethylene

MA Maleic anhydride

MAPP Maleated polypropylene

MDI Methylene diphenyl diisocyanate

$m$-TMI $\quad m$-Isopropenyl- $\alpha, \alpha$-dimethylbenzyl isocyanate

NMR Nuclear magnetic resonance

PBAT Polybutylene adipate-co-terephthalate

PBI Phenylbutyl isocyanate

PBNCO Polybutadiene isocyanate

PBS Poly(butylene succinate)

PCL Poly( $\varepsilon$-caprolactone)

PE Polyethylene

PEGME Poly(ethylene glycol) methyl ether

PI Phenyl isocyanate

PLA Poly(lactic acid)

pMDI Polymeric methylene diphenyl diisocyanate

PP Polypropylene

PPGME Poly(propylene glycol) monobutyl ether

PTHF Poly(tetrahydrofuran)

SEM Scanning electron microscopy

SNCs Starch nanocrystals

TDI Toluene diisocyanate

TEM Transmission electron microscopy

WF Wood flour

WPCs Wood-polymer composites

XPS X-ray photoelectron spectroscopy

XRD X-ray diffraction 


\section{Introduction}

Wood-polymer composites (WPCs) are a special group of composite materials, which are defined as composites consisting of one or more lignocellulosic fillers and one or a mixture of polymers. Incorporation of lignocellulosic fillers reduces costs and provides specific properties of composites, among others, enhanced mechanical performance, high stiffness, corrosion resistance, reduced environmental impact, higher usage of recycled and waste materials, renewable nature and sometimes even biodegradability. Moreover, compared to the mineral fillers (e.g., silica, calcium carbonate, etc.), the application of lignocellulosic fillers reduces wear and potential damage caused to the processing equipment. Considering these advantages, WPCs are more often regarded as an exciting alternative for polymers and composites conventionally applied in the building and automotive industry (Andrzejewski et al. 2019; Barczewski et al. 2019; Formela et al. 2016).

Current research on the development of wood-polymer composites can be assigned to two main trends. The first research trend focuses on decreasing the costs of materials used for manufacturing this type of composites (e.g., searching for a new source of lignocellulosic fillers from different kinds of agricultural wastes, application of recycled polymers, etc.). The second direction is searching for new methods to improve the interfacial interactions between often hydrophobic polymer matrix and hydrophilic lignocellulosic fillers, which affect their final performance properties. Compatibility, and to be more precise, lack of compatibility between matrix and lignocellulosic fillers is one of the main problems associated with the manufacturing of WPCs (Bledzki et al. 1998). Liu et al. (2014) indicated that the type of source of lignocellulosic fibers has a significant effect on the performance of composites. Significant differences in chemical structure and polarity of the components used usually result in their weak interfacial adhesion. Therefore, it is essential to improve the compatibility between the lignocellulosic filler and polymer matrix, as strong interfacial interactions are crucial to achieving the satisfactory mechanical properties of composites (Chan et al. 2017). Such an approach may be realized by providing possibilities for chemical bonding of modified lignocellulosic filler with functional groups present in the polymer backbone or by changing the character of the fillers' surface from hydrophilic to hydrophobic, simultaneously enhancing the affinity of the filler toward polymer matrix (Wang et al. 2017).

Depending on the chemical structure of filler and, most of all, polymer matrix, interfacial interactions can be divided according to their nature, but the most important are interactions based on intermolecular forces, for example, hydrogen bonds and stronger covalent bonds. Obviously, in most cases, covalent bonds are more efficient because they provide a permanent connection between phases. At present, numerous routes aimed at improving the interactions between the matrix and filler have been developed (Gallos et al. 2017). Generally, they can be divided into two main groups: matrix-based and filler-based strategies.

The matrix-based methods for enhancing interfacial interactions in WPCs are based on the grafting of various chemical compounds to the backbone of the 
polymer macromolecules. These strategies are mostly realized by the incorporation of a separately prepared compatibilizer. It is usually grafted polymer, which has the same or similar backbone to a matrix, providing their miscibility, and grafted functional groups able to bond with the filler surface. Grafting of various compounds to polymer chains is often realized by radical mechanisms. An example is presented in Fig. 1.

For their efficient application, a similar processing window should characterize the compatibilizers and the applied matrix. Such an effect would guarantee their effective processing and lack of decomposition. Moreover, they should be able to provide additional interactions between matrix and filler, enhancing the compatibility of phases. Enhancement of compatibility may result from physical or chemical interactions depending on the type and chemical structure of the compatibilizers. By far the most popular compatibilizers, which have been commercially available for many years, are polyolefins functionalized with maleic anhydride (MA). They are miscible with the most popular matrices applied to WPCs-polyethylene (PE) and polypropylene (PP) (Bettini et al. 2010; Lai et al. 2003). Their popularity is associated with the ability of maleic anhydride to react with the most popular functional groups present on the surface of lignocellulosic fillers-hydroxyl groups. The scheme of such interactions is presented in Fig. 2 (Hejna et al. 2019).

To enhance the compatibility of WPCs, except for MA, polymers may also be grafted with acrylic acid ( $\mathrm{Li}$ and Matuana 2003), glycidyl methacrylate (Pracella et al. 2006) or silanes (Nachtigall et al. 2007). Although their application did not show very significant effects, enhancement of tensile or flexural strength was observed, but it was lower than $20 \%$ and often accompanied by deterioration of other mechanical parameters.

As mentioned above, it is very beneficial to create strong, covalent bonds between polymer matrix and filler particles. Therefore, other groups of compounds, which are considered as effective for WPCs' compatibilization, are isocyanates. Their effectiveness is associated with the high reactivity of isocyanate groups (Karmarkar et al. 2007). The most common isocyanate is methylene diphenyl diisocyanate (MDI) and its polymeric form (pMDI). However, it has mainly been used for enhancement of the performance of WPCs via filler-based strategies.

The application of isocyanates may also be very beneficial for the WPCs based on the polyolefin matrices, which are by far the most popular in the manufacturing of WPCs, accounting for $85-89 \%$ of market value over the last years, so they are a very important field of research (Market Research Report 2018). Due to the limited
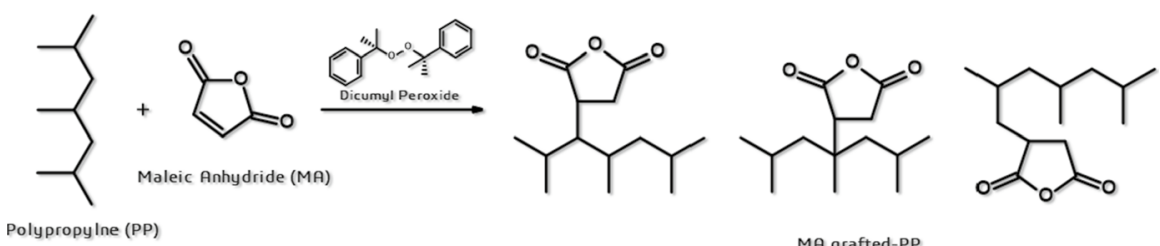

MA grafted-PP

Fig. 1 Mechanism of peroxide radical initiated grafting of MA onto PP 


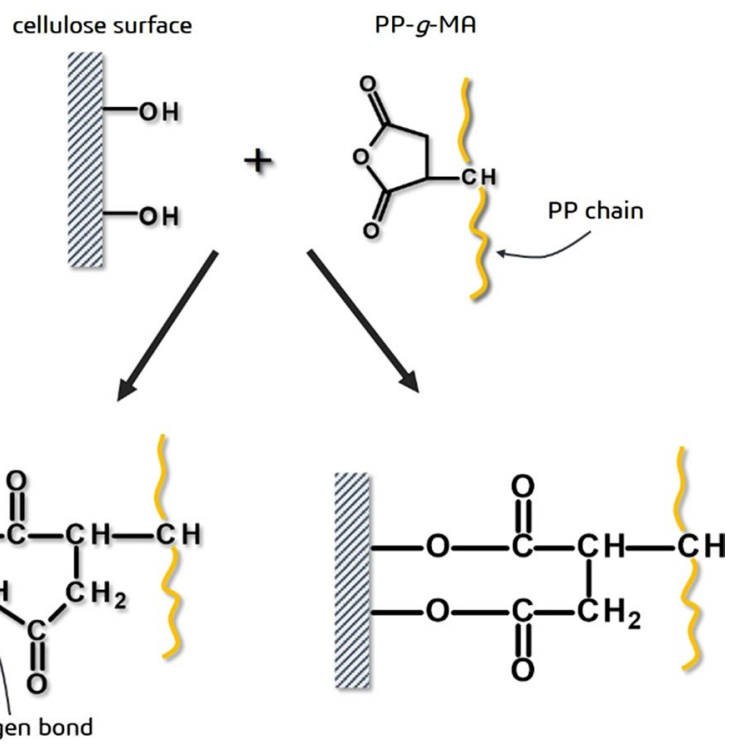

Fig. 2 Schematic of grafting reaction of PP functionalized by MA onto cellulose (Hejna et al. 2019)

possibility for covalent bonding with polyolefins, compatibilizers are often aimed at partial masking of the hydrophilicity of fillers, which enhances the compatibility of the system, because of the hydrophobic character of polyolefins (Joly et al. 1996).

On the other hand, other polymers may also be applied, for example, poly(vinyl chloride), polyurethanes, thermoplastic starch, or biodegradable polyesters, whose popularity has been increasing over the last years (European Bioplastics 2019). Their applications are based on the increasing awareness of society, related to the excessive production and use of petroleum-based plastics. These issues may be a serious threat to the environment, so research works associated with pro-ecological solutions are becoming more popular. Generally, these matrices show a significantly more hydrophilic character compared to polyolefins, which is also related to the presence of various functional groups in their backbones. In such a case, filler modifications may be performed to create hydrogen bonds or even more stable covalent bonds at the interphase.

Over the last decades, multiple review works related to the chemical modification of natural fibers to enhance the performance of polymer composites have been published by different research groups (George et al. 2001; Kabir et al. 2012; Kalia et al. 2009; Mohit and Arul Mozhi Selvan 2018). These works emphasized the importance of interfacial interactions in polymer composites filled with lignocellulosic fillers and summarized literature reports associated with this issue. The authors mentioned numerous methods of filler modification, from which the most popular and most widely described are alkali treatment, silanization, acetylation, maleation, acrylation, or permanganate treatment. Other, less common methods of modification, including fatty acid modification, sodium chloride treatment, benzoylation, triazine, or isocyanate treatment, were rather scarcely described and analyzed. Modification 
with isocyanates was rather briefly mentioned, and despite the multiplicity of available literature reports, only a few of them were described. Therefore, the aim of the presented paper was to summarize and analyze recent literature reports regarding this issue.

It is also essential that, regardless of the selected approach, most of the modification procedures reported in the literature are based on the batch processes. They often require the presence and use of high amounts of solvents, resulting in the high final costs of the modified natural fillers and limiting their further applications. Therefore, lately, more and more attention has been paid to in situ modifications performed during reactive processing of WPCs, for example, melt compounding in the extruders. Nevertheless, published information regarding continuous methods of lignocellulosic filler modification is still rather limited (Formela et al. 2018). From both economic and ecological points of view, this method seems to be a very attractive solution for effective fillers functionalization.

\section{Application of isocyanates}

As mentioned above, isocyanates can be considered as an exciting group of compounds for enhancement of interfacial interactions in WPCs. Their application as compatibilizers is very beneficial, because of their high reactivity and ability to create stable covalent bonds with functional groups present on the surface of lignocellulosic fillers, as well as in the structure of many polymers. The latter effect is very pronounced for polar polymer matrices, including biodegradable ones, such as poly(lactic acid) (PLA), poly( $\varepsilon$-caprolactone) (PCL), or thermoplastic starch, whose popularity in the WPCs production is growing (Jun 2000; Rensch and Riedl 1992; Zhao et al. 2008). Schematic reactions are presented in Fig. 3.

Moreover, some authors, especially in the case of filler modifications, are proposing the generation of polyureas or polyisocyanurates, which are settling on the surface of lignocellulosic fillers changing their adhesion to polymer matrices (Fig. 4) (Johns 1982; Ni and Frazier 1998). In the presence of humidity, its reactions with free isocyanate groups are hard to avoid. Therefore, amines and, consequently, urea groups are formed, which can further react with isocyanates generating biuret groups. On the other hand, at the higher reaction temperature, the trimerization

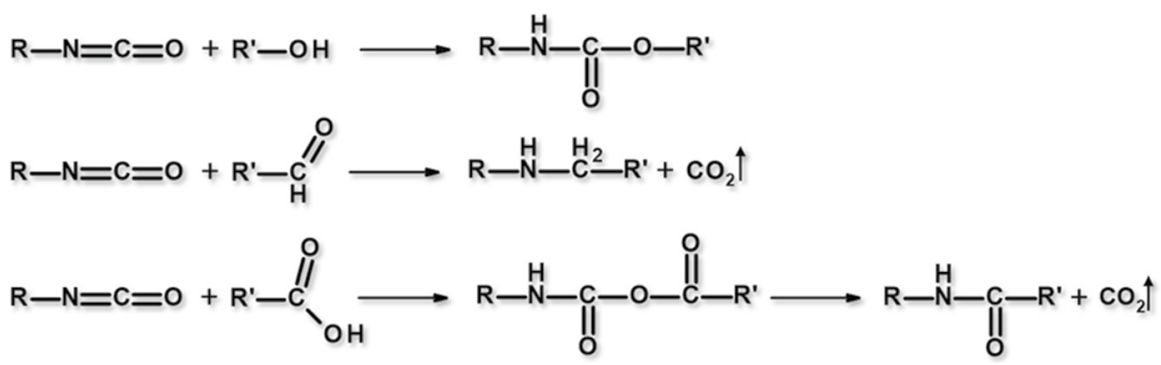

Fig. 3 Reactions of isocyanates with functional groups present on the surface of lignocellulosic fillers 


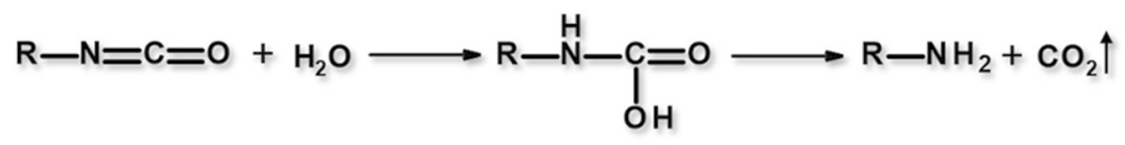<smiles></smiles><smiles>[R]NC(=O)N([R])C(=O)N[R]</smiles><smiles></smiles>

Fig. 4 Scheme of the possible generation of polyureas or polyisocyanurates during the modification with isocyanates (Johns 1982; Ni and Frazier 1998)

of isocyanates may occur, resulting in the formation of isocyanurates. Although in these cases, fewer urethane bonds may be formed, the presence of ureas and isocyanurates should still be considered beneficial due to increased possibility of hydrogen bonding with polymer matrices.

It is also very important that isocyanates have been commonly used in the plastics industry for many years; hence, they are well known and analyzed. The most popular ones are methylene diphenyl diisocyanate and toluene diisocyanate (TDI), which cover over $90 \%$ of the global market, followed by hexamethylene diisocyanate (HDI) and isophorone diisocyanate (IPDI), which stand for less than 5\%. These compounds, as well as less popular ones, which were already evaluated as modifiers for WPCs, are presented in Table 1.

An important issue that is often raised in the case of various applications of isocyanates is their toxicity. According to commonly used Globally Harmonized System of Classification and Labelling of Chemicals and NFPA 704 system, the majority of isocyanates are considered as a toxic, irritant, as well as health and environmental hazard (Table 1), which is associated with the high reactivity of unbound isocyanate groups (European Parliament and the Council 2008; Musk et al. 1988; NFPA 2017). However, after reaction with other functional groups and generation of stable covalent bonds, their toxicity is no longer considered as a threat. Such effect is observed in the case of the manufacturing of polyurethanes, which are commonly applied as biomedical grade materials during the production of, for example, catheters, blood bags, or various implants (Zdrahala and Zdrahala 1999). A similar case is observed for the introduction of isocyanate-modified fillers into WPCs when the 
Table 1 Isocyanates applied as modifiers to wood-polymer composites

\begin{tabular}{|c|c|c|c|c|c|c|c|c|}
\hline \multirow{2}{*}{$\begin{array}{c}\text { Abbreviated } \\
\text { name }\end{array}$} & \multirow[t]{2}{*}{ Chemical structure } & \multirow{2}{*}{$\begin{array}{c}\text { Molar mass } \\
(\mathrm{g} / \mathrm{mol})\end{array}$} & \multirow{2}{*}{$\begin{array}{l}\text { Density } \\
\left(\mathrm{g} / \mathrm{cm}^{3}\right)\end{array}$} & \multirow{2}{*}{$\begin{array}{l}\text { Melting point } \\
\left({ }^{\circ} \mathrm{C}\right)\end{array}$} & \multirow[t]{2}{*}{ GHS pictograms } & \multicolumn{3}{|c|}{$\begin{array}{c}\text { NFPA } 704 \\
\text { codes }\end{array}$} \\
\hline & & & & & & & & \\
\hline MDI & & 250.3 & 1.18 & 40 & & 1 & 1 & 0 \\
\hline pMDI & & $-^{\mathrm{a}}$ & $1.22-1.25$ & $<10$ & & 2 & 1 & 1 \\
\hline TDI & & 174.2 & 1.21 & 22 & & 3 & 1 & 1 \\
\hline HDI & & 168.2 & 1.05 & -67 & & 4 & 1 & 1 \\
\hline IPDI & & 222.3 & 1.06 & -60 & & 2 & 1 & 1 \\
\hline HMDI & & 262.4 & 1.07 & 26 & & 4 & 1 & 1 \\
\hline PBI & & 175.2 & 1.02 & $-^{\mathrm{a}}$ & & $-^{\mathrm{a}}$ & $-{ }^{\mathrm{a}}$ & $-^{\mathrm{a}}$ \\
\hline$m$-TMI & & 201.3 & 1.02 & $-^{\mathrm{a}}$ & & $-{ }^{\mathrm{a}}$ & $-{ }^{\mathrm{a}}$ & $-^{\mathrm{a}}$ \\
\hline LDI & & 226.2 & 1.13 & $-^{\mathrm{a}}$ & & $-{ }^{\mathrm{a}}$ & $-{ }^{\mathrm{a}}$ & $-^{\mathrm{a}}$ \\
\hline PI & & 119.1 & 1.09 & -30 & & 4 & 2 & 1 \\
\hline
\end{tabular}

${ }^{a}$ No data available

toxic effect should be eliminated (or at least significantly reduced), due to the excess of hydroxyl groups of fillers. Therefore, considering that during the modification of WPCs, isocyanates can covalently bond with matrix and filler phases, they should not be treated as hazardous toward human health.

Moreover, as mentioned above, a wide range of isocyanates have already been evaluated as modifiers for WPCs, which are associated with their multiplicity, even despite the low share of the market. As can be seen in Table 1, they are different in the chemical formula, molecular weight, spatial structure, functionality, or the presence of various chemical structures, for example, aromatic rings. Such aspects of modifiers may noticeably affect the properties of modified filler or polymer matrix, among others, in terms of their crystallinity, wettability, polarity, or affinity for 
various chemicals (Zhang et al. 2014). As a result, mechanical performance, thermal properties, absorptivity, or mechanism and rate of degradation may be engineered by a proper selection of modifier of filler or matrix.

\section{Matrix-based strategies}

As mentioned above, matrix-based strategies are related to the grafting of the different chemical compounds to the backbone of polymer macromolecules or the introduction of the compatibilizers, which are miscible with polymer matrix due to similarities in structure and physical or chemical properties. Such an assumption was made by Pickering and Ji (2004), in their work related to the compatibilization of PP-pine fiber composites with pMDI. The authors assumed that the hydrocarbon chain of applied isocyanate could interact with the hydrophobic polymer chain of PP by Van der Waal's forces. Therefore, no actual grafting was performed; pMDI in the amount of $2 \mathrm{wt} \%$ was only premixed with the matrix prior to the addition of filler during melt blending. For comparison, the authors also prepared two types of coupling agents based on maleated polypropylene (MAPP). Performed modifications had a negligible influence on the strength of the PP matrix, which varied from 22.3 to 23.6 MPa. (For unmodified PP, it was 23.1 MPa.) Interactions between pMDI and PP matrix were rather weak because incorporation of this compatibilizer (in the amount of 0-4 wt\%) to analyzed WPCs (0-50 wt\% of filler) resulted in tensile strength values between 21.5 and $24.0 \mathrm{MPa}$, while application of maleated PP resulted even in the exceeding of 50.0 MPa. A combination of two types of analyzed coupling agent did not cause any synergistic effects. The mechanical performance was similar as in the case of incorporation of maleated PPs alone. Therefore, to use the potential of isocyanates more efficiently, they should be chemically bonded to the polymer matrix.

This hint was used by Karmarkar et al. (2007), who performed melt phase grafting of $m$-isopropenyl- $\alpha, \alpha$-dimethylbenzyl isocyanate ( $m$-TMI) onto isotactic polypropylene in the reactive extrusion process using dicumyl peroxide (DCP) as radical initiator. $m$-TMI grafting on PP via reactive extrusion was first reported. The application of this modifier was analyzed for the first time by Braun and Schmitt (1998), who used $m$-TMI- $g$-PP as a compatibilizer for PP/polyamide 6 and PP/polyamide 66 blends. However, in that case grafting was performed in the periodic process using an internal mixer. Karmarkar et al. (2007), under the applied conditions (temperatures alongside the extruder barrel-180/190/200/180 ${ }^{\circ} \mathrm{C}$ and rotary speed of $90 \mathrm{rpm}, 10 \mathrm{wt} \%$ of $m$-TMI and DCP), achieved $5.2 \mathrm{wt} \%$ degree of grafting for a relatively short reaction time of $4.5 \mathrm{~min}$ (residence time of material in extruder barrel). Reactive extrusion was also applied to the manufacturing of WPCs. Wood fibers were incorporated in the amount of $10-50 \mathrm{wt} \%$, and the coupling agent was applied in the amount of $5 \mathrm{wt} \%$ relative to the fiber content. The introduction of the coupling agent resulted in a significant improvement in mechanical performance. In the case of tensile properties, up to $20 \mathrm{wt} \%$ content of wood fiber, hardly any difference was observed between samples with and without compatibilizer. However, for higher loading levels, a noticeable impact was noted. For $50 \mathrm{wt} \%$ content of the 
filler, compatibilization resulted in a 57\% increase in tensile strength. The effect was even more substantial for flexural strength, which was increased by $\sim 80 \%$ when the coupling agent was applied. On the other hand, a slight decrease in impact strength was observed, which was related to the stiffening of the composite due to bonding between matrix and filler phases, which was later confirmed in other research (Chauhan et al. 2009).

The same isocyanate was also applied in works by Guo and Wang (2008) and Guo et al. (2011, 2013). The authors also used reactive extrusion to graft selected isocyanate onto the PP chain via radical mechanism using DCP. No details about process parameters were provided. However, the grafting degree was determined as $1.8 \mathrm{wt} \%$. Next, PP composites filled with wood flour (WF) were prepared using reactive extrusion. In their later work (Guo et al. 2013), the influence of filler loading (from 0 to $50 \mathrm{wt} \%$ ) and compatibilizer content (from 0 to $10 \mathrm{wt} \%$ ) on the properties of composites were investigated. Based on the mechanical properties-tensile and flexural strength as well as flexural modulus, optimum content of filler was determined as $40 \mathrm{wt} \%$. Higher loadings caused deterioration of mechanical performance, probably due to unfavorable agglomeration of WF particles. Following the same protocol, optimum compatibilizer content was determined as $6 \mathrm{wt} \%$. Surprisingly, according to the authors, its higher contents caused plasticization of the PP matrix, because of low molecular weight and short molecule chain. However, the same PP was used for the preparation of compatibilizer and composites, and despite that, no plasticization of PP in the compatibilizer was noted. Enhanced compatibility of composites associated with the use of $m$-TMI- $g$-PP was confirmed by scanning electron microscopy (SEM) analysis and dynamic mechanical analysis (DMA) results. Then, in their earlier work, the authors used the optimum formulations to analyze the impact of compatibilization on thermal properties. Only small changes were observed for differential scanning calorimetry (DSC) analysis. However, interestingly, incorporation of WF into PP, with and even without the use of compatibilizer, enhanced the thermal stability of the composite.

Guo et al. (2019) grafted isocyanate silane (IS) onto polypropylene in the presence of dicumyl peroxide as a radical initiator during the reactive extrusion process. Unfortunately, no details regarding conditions of the process and the resulting degree of grafting were provided, neither in this nor in previous works of the research group. Resulting isocyanate silane grafted PP (PP- $g$-IS) was used to replace the PP matrix (up to $10 \mathrm{wt} \%$ ) in composites filled with wood flour. Thanks to the complex chemical structure, applied compatibilizer noticeably enhanced the mechanical performance of analyzed materials. Incorporation of 6 wt $\%$ increased tensile strength from 20.6 to $40.4 \mathrm{MPa}$ and flexural strength from 32.7 to $59.1 \mathrm{MPa}$. Such a significant improvement is related to the multiplicity of interactions between all applied components. PP chain of compatibilizer was able to entangle with PP matrix, while silanol and isocyanate functional groups were connecting with the hydroxyl groups of the filler via hydrogen and covalent bonds, respectively. As a result, strong interfacial adhesion was established, which was confirmed by SEM analysis. However, excessive loading of compatibilizer led to unfavorable changes in mechanical performance. Improved adhesion was also expressed by the enhancement of composites' stiffness and restricted 
molecular motions. Slight improvement in PP phase thermal stability was also observed.

Except for polyolefins, modification with isocyanates was also investigated for other matrices, which can be used in the manufacturing of WPCs, for example, starch, poly(lactic acid), or poly(butylene succinate) (PBS). Hosseinpourpia et al. (2018) modified pea starch and dextrin with isophorone diisocyanate using dibutyltin dilaurate (DBTDL), commonly used in the polyurethane industry as a catalyst. Authors modified selected natural polymers by solution method, with $\mathrm{NCO} / \mathrm{OH}$ functional groups ratio in the range of 3-6. The efficient modification was confirmed by elemental analysis, which indicated a significant increase in the nitrogen content, as well as Fourier transform infrared spectroscopy (FTIR) and nuclear magnetic resonance (NMR) spectroscopy, which pointed to the presence of urethane bonds and free isocyanate groups present on the surface of starch and dextrin. The authors also noticed an enhancement of the thermal stability of starch by 16 and $27{ }^{\circ} \mathrm{C}$, respectively, for $\mathrm{NCO} / \mathrm{OH}$ ratio of 3 and 6 , which confirmed previously published research (Valodkar and Thakore 2010). In the case of starch and dextrin, a drop in the glass transition temperature was observed, which was associated with the decreased amount of free hydroxyl groups and reduction in the number of hydrogen bonds between polymer chains (GómezFernández et al. 2017). It was also confirmed by the reduced water vapor sorption of analyzed polymers, which indicated decreased hydrophilicity. Generally, the presented results indicate that modification of starch with isocyanates can be very promising for its application to the manufacturing of WPCs.

Nevertheless, until now, modifications of the above-mentioned polymers with isocyanates have mainly been used for the compatibilization of their blends (Meimoun et al. 2017) or the use of modified starch as intermediate in the manufacturing of polyurethanes (Da Róz et al. 2009). One of the first works associated with the application of isocyanates as coupling agents for such blends, in this case, starch/polycaprolactone, was published by Mani et al. (1998). The authors grafted toluene 2,4-diisocyanate to polycaprolactone and then performed the reaction with starch. The generation of urethane linkages was confirmed by FTIR analysis. Such a prepared compound was used as a compatibilizer for starch/PCL blends and caused noticeable enhancement of mechanical performance and an increase in tensile strength from 4.4 to $19.0 \mathrm{MPa}$. Improved interfacial interactions were caused by finer dispersion of starch and smoother interface between phases confirmed by SEM and transmission electron microscopy (TEM) micrographs.

Later, Kweon et al. (2000) analyzed the modification of PCL with three isocyanates: TDI, MDI, and HDI. Grafting of isocyanates was performed in bulk without the application of catalysts with $\mathrm{NCO} / \mathrm{OH}$ ratios of 3:2 and 5:2. After the removal of unreacted isocyanates, the authors measured the content of isocyanate groups attached to PCL, which was similar, independent of the NCO/ $\mathrm{OH}$ ratio applied; therefore, lower excess was chosen. Modified polycaprolactone was reacted with starch, which was previously dissolved in dimethyl sulfoxide (DMSO), just as in the work by Mani et al. (1998). The efficiency of grafting was hardly affected by the isocyanate structure. However, the introduction of MDI enhanced the thermal stability of analyzed blends. Degradation temperature was 
increased from 290 to $305{ }^{\circ} \mathrm{C}$, while modification with TDI resulted in a decrease to $245{ }^{\circ} \mathrm{C}$.

Ohkita and Lee (2004) conducted similar research for PLA and PBS blends with starch. The authors performed in situ compatibilization of blends during their manufacturing with lysine diisocyanate (LDI) and hexamethylene diisocyanate. The application of both modifiers caused a noticeable enhancement in the blends' compatibility and mechanical performance. In the case of PLA and PBS-based blends (50:50 ratio with starch), 84 and 144\% increase in tensile strength was observed. An increase in Young's modulus was also observed. In both cases, the more substantial impact was noticed for LDI, which was ascribed by the authors to its branched structure and carbonyl group, which strengthened interactions with polymer matrices via hydrogen bonds. The influence of starch content in blends was also investigated, and it is worth to mention that incorporation of diisocyanates into analyzed blends allowed to maintain the tensile strength of blends containing up to $50 \mathrm{wt} \%$ of starch almost at the level of pure PBS and PLA. Improvement in the compatibility of blends was also confirmed by microscopic analysis.

Although these works are related to compatibilization of starch/polymer blends, published results may also be used in the manufacturing of WPCs, due to some similarities in chemical structure between analyzed polymers (mostly starch) and lignocellulosic fillers (mainly in the case of functional groups), which is presented in Fig. 5.

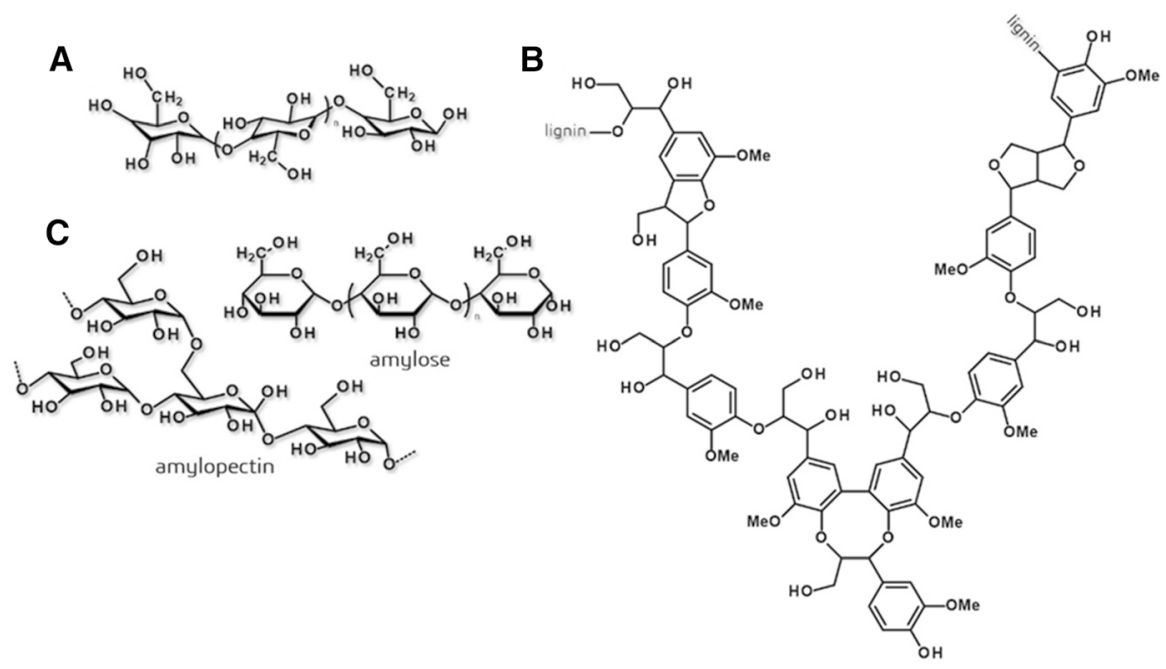

Fig. 5 Chemical structure of a cellulose, b lignin, and $\mathbf{c}$ starch 


\section{Filler-based strategies}

Filler-based strategies are based on the affinity of the free isocyanate groups toward hydroxyl groups present on the surface of various lignocellulosic fillers, often composed mainly of cellulose and lignin (Fig. 5). As mentioned above, depending on the type of applied polymer matrix, such treatments may be aimed at reducing the hydrophilicity of filler or providing the possibility for creating interfacial covalent bonding.

In their works, Maldas et al. $(1988,1989)$ comprehensively investigated the impact of isocyanate modification of different wood-based fillers on the properties of composites based on PS. The authors analyzed spruce and aspen sawdust, with varying particle size, modified with pMDI, TDI, and HDI. Noticeably, the best results were observed for modification with pMDI, which was ascribed to the presence of aromatic rings in this modifier and its polymeric nature, which provided more continuity at the interphase. Due to the noticeably smaller particle size and lack of polymeric character, TDI was not so effective. However, it still provided a significantly more substantial enhancement of mechanical performance compared to HDI. In Table 2, the effects of the modification performed are presented as a percentage change of various mechanical parameters. The authors also analyzed the influence of pretreatment methods of the filler, so they introduced wood sawdust, explosion pulp, and chemithermomechanical pulp (CTMP) generated from spruce and aspen. The most beneficial effects were obtained with the use of CTMP, which was ascribed to the most effective separation of fibers from wood chips, hence the highest specific surface area, which increases the size of the interphase. Similar investigations regarding polyethylene-based composites were described by Raj et al. (1989, 1990) from the same research group. Just as in the case of PS, pMDI was found to be the most beneficial modifier, which was related to its polymeric nature. However, the application of HDI provided

Table 2 Percentage changes in the mechanical performance of PS after incorporation of 30 wt $\%$ of various wood fillers modified with 2 wt\% of isocyanates (Maldas et al. 1988, 1989)

\begin{tabular}{|c|c|c|c|c|c|}
\hline Wood type & Particle size & Isocyanate & Tensile strength & Elongation at break & Young's modulus \\
\hline \multirow[t]{4}{*}{ Spruce } & \multirow[t]{4}{*}{20 mesh } & - & $\uparrow 3.2$ & $\downarrow-23.0$ & $\uparrow 35.8$ \\
\hline & & pMDI & $\uparrow 19.9$ & $\downarrow-19.2$ & $\uparrow 40.9$ \\
\hline & & TDI & $\uparrow 12.0$ & $\downarrow-26.9$ & $\uparrow 27.7$ \\
\hline & & HDI & $\downarrow-2.9$ & $\downarrow-34.6$ & $\uparrow 15.1$ \\
\hline \multirow[t]{4}{*}{ Spruce } & \multirow[t]{4}{*}{60 mesh } & - & $\uparrow 9.1$ & $\downarrow-3.8$ & $\uparrow 13.8$ \\
\hline & & pMDI & $\uparrow 22.2$ & $\downarrow-19.2$ & $\uparrow 32.7$ \\
\hline & & TDI & $\uparrow 14.3$ & $\downarrow-26.9$ & $\uparrow 37.7$ \\
\hline & & HDI & $\uparrow 6.1$ & $\downarrow-38.5$ & $\uparrow 35.8$ \\
\hline \multirow[t]{2}{*}{ Aspen } & \multirow[t]{2}{*}{20 mesh } & - & $\downarrow-7.9$ & $\downarrow-23.1$ & $\uparrow 18.2$ \\
\hline & & pMDI & $\uparrow 10.2$ & $\downarrow-26.9$ & $\uparrow 39.0$ \\
\hline \multirow[t]{2}{*}{ Aspen } & \multirow[t]{2}{*}{60 mesh } & - & $\uparrow 1.8$ & $\uparrow 3.8$ & $\uparrow 13.2$ \\
\hline & & pMDI & $\uparrow 17.5$ & $\downarrow-23.1$ & $\uparrow 40.3$ \\
\hline
\end{tabular}


superior effects on the use of TDI, which was associated with the similarity between C6 chain in HDI and polyethylene backbone. Moreover, modification with pMDI provided a higher level of mechanical performance enhancement compared to the analyzed silanes.

The effectivity of the pMDI was later confirmed by other researchers. George et al. $(1996,1997)$ investigated the compatibilization of polyethylene/pineapple leaf fiber composites with polymethylene polyphenyl isocyanate. Modification of fibers with $5 \mathrm{wt} \%$ of pMDI resulted in a significant enhancement of the mechanical performance of resulting composites, which can be seen in Table 3. A decrease in elongation at break was noted. However, it is typical during the enhancement of tensile strength and modulus of a material. The authors ascribed positive changes in the mechanical performance of composites to the reduced hydrophilicity of fibers and Van der Waals interactions between PE chains and relatively long chains of pMDI, which consisted of methylene groups and six-membered aromatic rings (Table 1). The stiffening of composites due to strengthened interfacial interactions was confirmed by dynamic mechanical analysis. Moreover, isocyanate modification slightly enhances the thermal stability of composites.

A research group from Oregon State University used pMDI to improve properties of PP- and PE-based composites containing $40 \mathrm{wt} \%$ of wood flour. In the case of polyethylene composites (Geng et al. 2005), pMDI was used solely or in combination with stearic acid. The addition of $1.5 \mathrm{wt} \%$ of pMDI resulted in a $\sim 10 \%$ increase in modulus of rupture and modulus of elasticity, while the combination with $0.5 \mathrm{wt} \%$ of stearic acid led to $\sim 90 \%$ and $\sim 20 \%$ improvement in these parameters. Enhanced compatibility of investigated composites could also be seen in the presented SEM images. Moreover, analyzed coupling agents were more effective than commercially available PE- $g$-MA.

For PP-based biocomposites (Zhang et al. 2004), the authors analyzed the incorporation of pMDI, PP- $g$ - $N$-vinylformamide (PP- $g$-VF), and their combinations. Results were also compared to those for composites compatibilized with commercial PP- $g$-MA. The best results, superior to those obtained when maleic anhydride was used, were obtained for a combination of pMDI and PP- $g$-VF. Microscopic analysis of these materials suggested that the enhancement of mechanical performance was due to the improved interfacial adhesion between matrix and filler. Moreover, such a coupling agent system resulted in a significant decrease in water uptake, which can be considered beneficial because it retards the degradation of biocomposites.

Table 3 Enhancement of composites' mechanical performance after modification of pineapple leaf fiber with 5 wt\% of pMDI (George et al. 1996, 1997)

\begin{tabular}{lllll}
\hline $\begin{array}{l}\text { Fiber } \\
\text { content } \\
(\%)\end{array}$ & $\begin{array}{l}\text { Tensile strength } \\
(\mathrm{MPa})\end{array}$ & $\begin{array}{l}\text { Young's modulus } \\
(\mathrm{MPa})\end{array}$ & $\begin{array}{l}\text { Elongation at break } \\
(\%)\end{array}$ & Tear strength $(\mathrm{kN} / \mathrm{m})$ \\
\hline 10 & $16.3 \rightarrow 20.0$ & $610 \rightarrow 1200$ & $10.8 \rightarrow 7.5$ & $72 \rightarrow 84$ \\
20 & $19.8 \rightarrow 32.4$ & $800 \rightarrow 1800$ & $9.2 \rightarrow 5.2$ & $81 \rightarrow 101$ \\
30 & $22.5 \rightarrow 35.0$ & $1100 \rightarrow 2500$ & $4.0 \rightarrow 3.0$ & $97 \rightarrow 105$ \\
\hline
\end{tabular}


Gwon et al. (2018) grafted TDI onto the surface of cellulose nanocrystals (CNCs) to reduce their polarity and enhance the dispersibility in the hydrophobic polypropylene matrix. Then, the suspension of modified CNCs in acetone was added to hot toluene, and powdered PP was introduced. The polymer dilute system was kept for $3 \mathrm{~h}$ to achieve homogeneity of suspension, and then toluene was evaporated. Such a process after $24 \mathrm{~h}$ of drying resulted in coated PP powder, which was then injection molded. Effective modification and generation of urethane bonds between CNCs and isocyanate were confirmed by FTIR analysis. Moreover, the dispersibility of modified CNCs in nonpolar toluene was significantly better than for neat CNCs, which indicated the reduction in the polarity of the surface. As a result, compatibility with PP matrix was noticeably improved, so $\sim 22$ and $\sim 14 \%$ rise in tensile strength and elongation at break was observed for $5 \mathrm{wt} \%$ loading of modified CNCs as a filler.

Qiu et al. (2005) introduced HDI as a modifier for PP/cellulose fibers and PP$g$-MA/cellulose fibers composites. The authors used 1.0, 2.5, and 5.0 pbw content of HDI, while the loading of filler was fixed at $30 \mathrm{wt} \%$. SEM analysis of fractured surfaces suggested improvement in interfacial adhesion with the increase in HDI content, independently of the presence of maleic anhydride. However, based on the tensile test results, the most beneficial content of the modifier was 1 pbw, because the further increase in its content did not result in further enhancement of mechanical performance; for PP matrix, even deterioration was noted. Such effect was

A
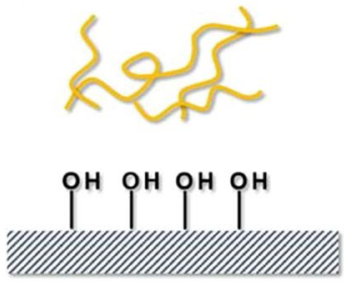

cellulose fiber

D

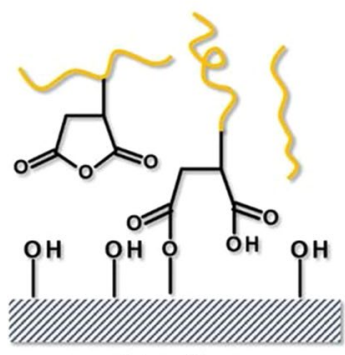

cellulose fiber
B

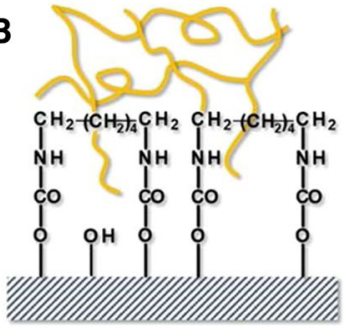

cellulose fiber

$\mathbf{E}$

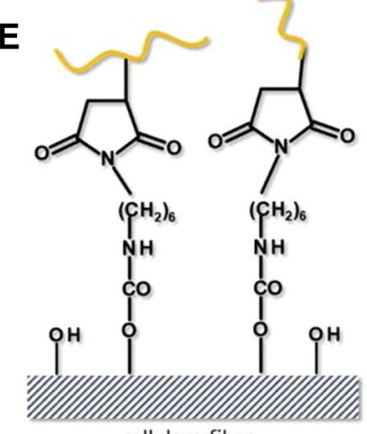

cellulose fiber

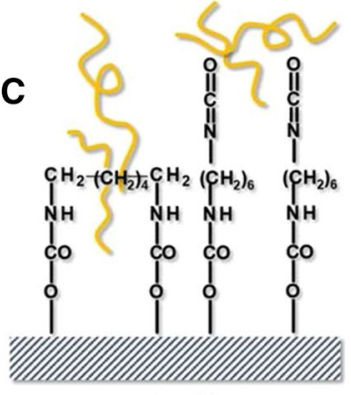

cellulose fiber

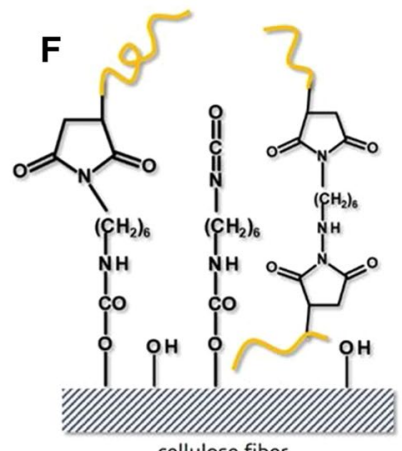

cellulose fiber

Fig. 6 Possible interactions between cellulose fibers and: a neat PP, b PP modified with lower content of HDI, c PP modified with a higher content of HDI, d neat PP- $g$-MA, e PP- $g$-MA modified with lower content of HDI, and f PP- $g$-MA modified with a higher content of HDI (Qiu et al. 2005) 
associated with the decrease in the samples' crystallinity with the addition of HDI, which reduced the strength of the polymer matrix, especially in the case of neat PP. For PP-g-MA, matrix reduction was not so strong. In Fig. 6, possible interactions responsible for the enhancement of interfacial adhesion in investigated composites are presented.

HDI was also used by Liew et al. (2018) for the modification of jute and bamboo fibers introduced into low-density polyethylene (LDPE) matrix. The authors obtained very promising results, because fiber modification performed according to the described method (periodic method based on solution treatment followed by 24-h drying) resulted in significant enhancement of the thermal stability of the composites-for $10 \mathrm{wt} \%$ loading of modified filler, the onset of decomposition was shifted by over $100{ }^{\circ} \mathrm{C}$. Such effect should be considered very beneficial from a technological point of view, because it would allow the incorporation of modified lignocellulosic fillers, which usually show relatively low thermal stability, into matrices requiring higher processing temperatures. Moreover, applied modification of fillers resulted in the enhancement of tensile strength and Young's modulus by 295 and $296 \%$, respectively, which was ascribed to the improved interfacial interactions, as proven by SEM analysis.

Lately, a comparative analysis of the application of four of the most popular diisocyanates: HDI, IPDI, MDI, and TDI, as compatibilizers of PLC/cellulose composites was performed (Hejna and Kosmela 2020). Cellulose filler, Arbocel UFC100, was modified with 5 and $15 \mathrm{wt} \%$ of diisocyanates and then introduced in the amount of $30 \mathrm{wt} \%$ into the PCL matrix. Independently of the type of modifier, significant enhancement of the mechanical performance was noted. The dynamic mechanical analysis revealed that all applied treatments resulted in the enhancement of the interfacial adhesion, which was confirmed by the results of tensile tests. The tensile strength was increased from the initial $13.71 \mathrm{MPa}$ to $22.91-28.72 \mathrm{MPa}$, depending on the type of diisocyanate. It was related to the stiffening of composite, expressed by the increase in Young's modulus by 4.3-25.3\%. Generally, better tensile performance was noted for aromatic diisocyanates than for aliphatic ones. Nevertheless, independently of the type and content of modifier, enhanced interfacial interactions resulted in higher brittleness of the composites, which were able to withstand a higher amount of stress. However, in the lower range of strains, therefore overall, a lower amount of energy was required to destroy them.

Various researchers also investigated less popular isocyanates or more complex procedures, for example Joseph et al. (1995, 1996) and Paul et al. (1997), who modified alkali-treated sisal fibers with urethane derivative of cardanol (CTDIC) obtained by mixing of cardanol with an excess of TDI, whose structure is presented in Fig. 7. Obtained derivative contained free isocyanate groups for further reaction with hydroxyl groups of filler. Such modifications resulted in noticeable improvement in the mechanical performance of PE-based composite containing $30 \mathrm{wt} \%$ of filler. Compared to untreated and solely alkali-treated samples, tensile strength was increased by 33 and $21 \%$, while modulus was increased by 32 and $22 \%$. Further, improvement in elongation at break was observed. However, the values of this parameter were still very low and did not exceed $4 \%$. These results were obtained for longitudinally oriented composites. For random distribution of filler, differences 
toluene 2, 4-diisocyanate

(TDIC)
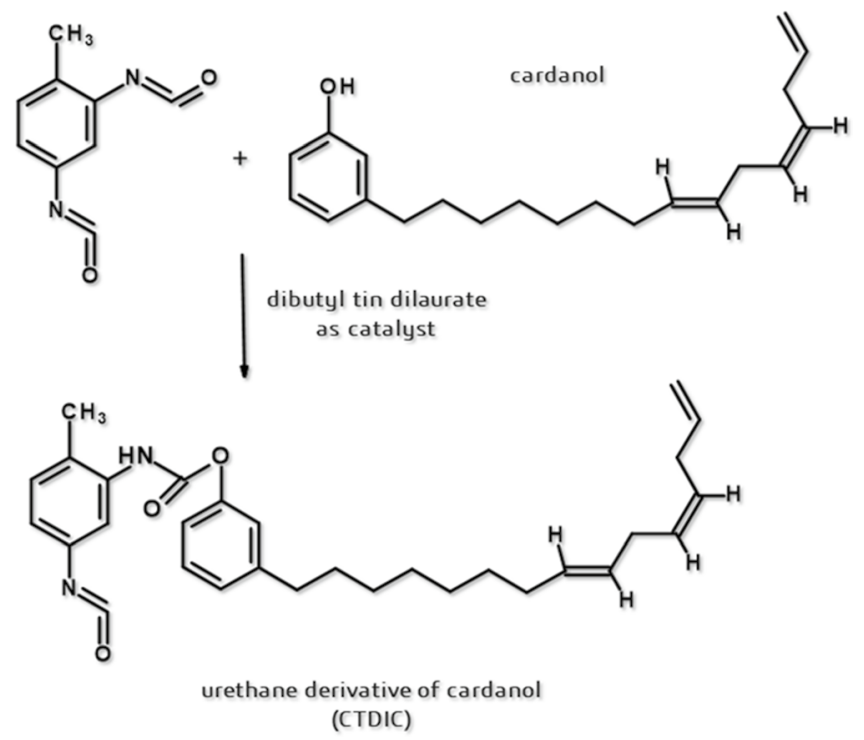

Fig. 7 Scheme for preparation of urethane derivative of cardanol (Joseph et al. 1995)

between alkali treatment and CTDIC treatment were not so significant and were lower than $10 \%$. The authors explained the enhancement of mechanical performance with the improved compatibility between the PE matrix and modified fillers due to long hydrocarbon chains present in the cardanol structure. Decreased hydrophilicity of fibers was also confirmed by the increase in resistivity and dielectric loss factor of composites after CTDIC treatment of filler.

Gironès et al. (2007) used phenol-blocked and butanol-blocked MDI to enhance interfacial interactions in PS-based composites filled with $30 \mathrm{wt} \%$ of bleached pine fibers and compared the results to the use of neat MDI. Unfortunately, the authors did not provide information about the content of the introduced compatibilizers. Nevertheless, the best results were obtained for the application of neat MDI, which

Table 4 Effect of isocyanate-based compatibilizers on mechanical properties of PS/bleached pine fibers composites (Gironès et al. 2007)

\begin{tabular}{lllll}
\hline Compatibilizer & Tensile strength $(\mathrm{MPa})$ & $\begin{array}{l}\text { Young's modu- } \\
\text { lus }(\mathrm{MPa})\end{array}$ & $\begin{array}{l}\text { Flexural strength } \\
(\mathrm{MPa})\end{array}$ & $\begin{array}{l}\text { Flexural } \\
\text { modulus } \\
(\mathrm{MPa})\end{array}$ \\
\hline- & $47.1 \pm 0.3$ & $3489 \pm 357$ & $83.3 \pm 1.1$ & $5241 \pm 119$ \\
MDI & $49.3 \pm 0.8$ & $3621 \pm 210$ & $87.9 \pm 1.2$ & $5133 \pm 188$ \\
Ph-blocked MDI & $49.1 \pm 0.8$ & $3644 \pm 181$ & $86.9 \pm 3.4$ & $5248 \pm 174$ \\
Bu-blocked MDI & $47.4 \pm 1.1$ & $3547 \pm 318$ & $83.4 \pm 4.1$ & $5062 \pm 177$ \\
\hline
\end{tabular}


can be seen in Table 4. Therefore, it can be concluded that the introduction of additional costly unit processes with significant environmental impact (use of organic solvents) is rather unnecessary.

Labet et al. (2007) modified the surface of starch nanocrystals (SNCs) with various polymers: poly(tetrahydrofuran) (PTHF), poly(propylene glycol) monobutyl ether (PPGME), and two types of poly(caprolactone) differing in molecular weight (PCL10000 and PCL42500). Except for PPGME, all other modifications were performed in three-step processes. The first step was to block one functional group of polymers with phenyl isocyanate, which was not required for PPGME, while the second step consisted of reaction with TDI. Complete modification processes lasted for about 10 days, including purification steps, which significantly affects the yield of the process since the authors modified only $2 \mathrm{~g}$ of SNCs. Efficient surface modification was confirmed by FTIR analysis, which indicated the presence of functional groups typical of applied polymers. According to X-ray diffraction (XRD) and DSC results, it can be concluded that the initial crystalline structure of SNCs was disrupted by the modifications performed, which was expressed by less defined peaks and lowering of melting temperature of starch with the increase in polymer chain length. Contact angles, measured only for PTHF and PPGME modifications (for PCL measurement was impossible due to low smoothness of the particle surface), were very close to literature values for these polymers, which indicated good coverage of the starch surface. Moreover, the polarity of the SNCs' surface was significantly reduced by more than $87 \%$.

To additionally enhance the effectivity of the fillers' modification by isocyanate treatment, some of the authors applied a catalyst, which is used in the manufacturing of polyurethanes to accelerate the generation of urethane groups during the reaction of isocyanate groups with hydroxyls - dibutyltin dilaurate (Nair and Thomas 2003).

Such an approach was used by Arjmand et al. (2012) during the modification of softwood fibers with TDI. First, the authors treated fibers with sodium hydroxide to remove any residual waxes and oils and activate the hydroxyl groups present on the surface. Next, TDI grafting $(10,15$, or $20 \mathrm{wt} \%$ by weight of fibers) catalyzed by DBTDL was performed in the toluene solution. After removing the excess of isocyanate, the calculated amount of cetyl alcohol was added together with other portions of the catalyst. The whole procedure lasted over a week, and its scheme is shown in Fig. 8. Modified fibers were used to prepare high-density polyethylene (HDPE)based composites by melt mixing. Chemical structure and effectiveness of modification were analyzed by FTIR spectroscopy, which indicated changes expected in the spectra. In Table 5, mechanical properties of prepared composites are presented as a function of applied fiber modification. It can be seen that isocyanate treatment and subsequent modification with cetyl alcohol significantly improved the compatibility of fibers with the HDPE matrix. Such an effect was ascribed to reduced polarity, also expressed by the reduction in the water absorption of the composites, which decreased from 2.47 to $1.72,1.52$, and $1.43 \%$, for 10,15 , and $20 \mathrm{wt} \%$ of TDI added, respectively.

Thielemans et al. (2006) performed a chemical modification of starch nanocrystals obtained by acid hydrolysis of waxy maize starch. They used 2,4-toluene diisocyanate to graft poly(ethylene glycol) methyl ether (PEGME) on the surface of 
A

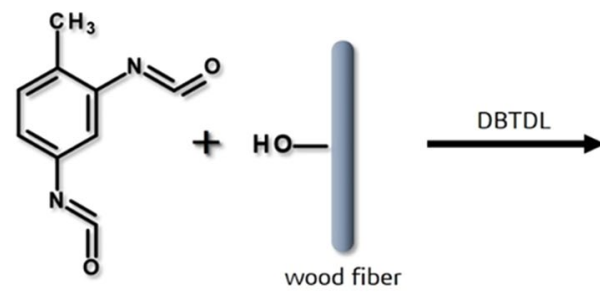

toluene 2, 4-diisocyanate (TDIC)

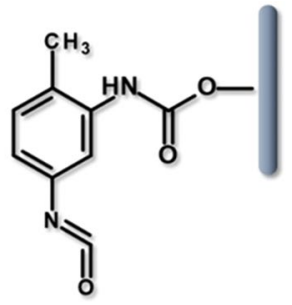

treatment of wood fiber with TDI

\section{B}

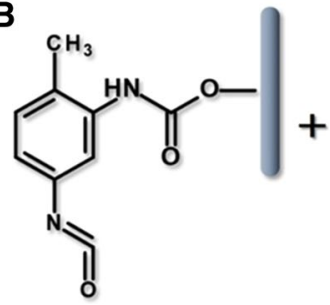<smiles>CCCCCCCCCCO</smiles>

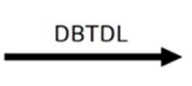<smiles>CCCOC(=O)Nc1ccc(C)c(NC(=O)OCC)c1</smiles>

Fig. 8 Possible reaction of $\mathbf{a}$ TDI with wood fiber and $\mathbf{b}$ free isocyanate group in TDI-treated wood fiber with cetyl alcohol (Arjmand et al. 2012)

Table 5 Mechanical performance of HDPE/softwood fibers composites (Arjmand et al. 2012)

\begin{tabular}{lrrrr}
\hline Property & Unmodified fibers & \multicolumn{4}{c}{ Modified by TDI $(\mathrm{wt} \%)$} \\
\cline { 3 - 5 } & & \multicolumn{1}{c}{10} & \multicolumn{1}{c}{15} & \multicolumn{1}{c}{20} \\
\hline Tensile strength (MPa) & $18.30 \pm 1.48$ & $23.23 \pm 0.50$ & $27.53 \pm 0.47$ & $29.99 \pm 0.37$ \\
Elongation at break (\%) & $4.01 \pm 0.11$ & $4.99 \pm 0.24$ & $5.11 \pm 0.13$ & $5.20 \pm 0.17$ \\
Young's modulus (GPa) & $1.39 \pm 0.09$ & $1.85 \pm 0.05$ & $2.00 \pm 0.05$ & $2.12 \pm 0.10$ \\
Flexural strength $(\mathrm{MPa})$ & $19.03 \pm 0.66$ & $22.90 \pm 0.49$ & $24.46 \pm 0.25$ & $28.10 \pm 0.52$ \\
Flexural modulus $(\mathrm{GPa})$ & $1.17 \pm 0.07$ & $1.40 \pm 0.02$ & $1.53 \pm 0.01$ & $1.62 \pm 0.02$ \\
Impact strength $\left(\mathrm{kJ} / \mathrm{m}^{2}\right)$ & $2.40 \pm 0.10$ & $3.50 \pm 0.33$ & $4.51 \pm 0.13$ & $5.22 \pm 0.25$ \\
\hline
\end{tabular}

particles. The first step consisted of combining TDI with PEGME. The reaction was catalyzed by DBTDL and was completed after $24 \mathrm{~h}$, as confirmed by FTIR measurements. The obtained compound was then used for lasting seven-day modification of SNCs, which were then purified in a relatively complex manner. Efficient surface modification was confirmed by FTIR and X-ray photoelectron spectroscopy (XPS). The polarity of the surface was reduced by $\sim 67 \%$, which could enhance the compatibility of modified particles with nonpolar polymer matrices.

Morelli et al. (2016) modified cellulose nanocrystals with phenylbutyl isocyanate (PBI) in a process catalyzed by DBTDL. However, the modification procedure was very complex, and except for specific modification steps lasting $30 \mathrm{~min}$, including two solvent exchange phases (with intermediate steps, a total of five 
organic solvents were used: toluene, acetone, dichloromethane, chloroform, and ethanol), sonification and drying, which lasted several days. Obtained modified CNCs were introduced into polybutylene adipate-co-terephthalate (PBAT), and their properties were determined. Applied modification of CNCs had hardly any effect on the tensile strength of the composites. It caused some enhancement; however, differences were in the range of standard deviation. A more significant impact was noted for thermal stability and water vapor permeability of composites. The onset of thermal degradation was retarded by 24,33 , and $21{ }^{\circ} \mathrm{C}$ for modification of $2.5,5.0$, and $10.0 \mathrm{wt} \%$ of $\mathrm{CNCs}$, respectively, while the permeability of water vapor was lowered by 63,54 , and $63 \%$. The authors ascribed these improvements to better compatibility and lowered void content in composites resulting from the performed modification of CNCs.

CNCs were also selected for modification by Girouard et al. (2016), who grafted IPDI on their surface, using DBTDL and 1,4-diazabicyclo[2.2.2] octane (DABCO) as catalysts. The whole modification process, including purification and drying, lasted around 2 days. Selectivity of both catalysts was compared by the analysis of ${ }^{13} \mathrm{C}$ NMR spectra of modified CNCs. For further preparation of polyurethane films, CNCs modified in the reaction catalyzed with DBTDL were selected. CNCs were introduced in the amount of 1 and $5 \mathrm{wt} \%$. FTIR spectroscopy indicated the presence of free isocyanate groups on the surface of modified CNCs, which were enhancing the compatibility of particles with a polyurethane matrix. Such an effect was confirmed by comparison of polarized light micrographs for samples with modified and neat CNCs, which indicated better dispersion and lower crystallinity for composites containing modified particles. Enhanced compatibility resulted in the enhancement of tensile properties. For all analyzed variants ( 1 and $5 \mathrm{wt} \%$ of modified and neat CNCs), an increase in tensile strength was noted. However, when modified CNCs were applied, 42 and 165\% higher values of this parameter were observed. Similar effects were observed in the case of the materials' toughness.

In addition, Gómez-Fernández et al. (2017) applied a catalyst during the modification of kraft lignin with isophorone diisocyanate. Their modification scheme included 24-h reaction conducted in tetrahydrofuran at $60{ }^{\circ} \mathrm{C}$ under nitrogen atmosphere, catalyzed by DBTDL, followed by at least three cycles of centrifugation and washing with fresh toluene. Then, modified kraft lignin was vacuumdried at $75{ }^{\circ} \mathrm{C}$ for $24 \mathrm{~h}$ and additionally kept under vacuum for the next $48 \mathrm{~h}$. Effective functionalization of kraft lignin and generation of urethane bonds on its surface were investigated and confirmed by a detailed analysis of its chemical structure, which consisted of FTIR, as well as liquid- and solid-state NMR spectroscopy and elemental analysis. As a result, around $50 \%$ of hydroxyl groups reacted with free isocyanate groups of IPDI. Modification of chemical structure also resulted in changes in surface energy, which reduced the agglomeration effect and lowered the particle size and should be considered beneficial for the manufacturing of composites. 


\section{Benefits and drawbacks of matrix- and filler-based strategies}

The main benefit of the matrix-based strategies is the permanent, covalent bonding between polymer matrix and diisocyanate. Grafting of the modifier via radical mechanism results in the generation of relatively strong $\mathrm{C}-\mathrm{C}$ bonds between these phases, which is often realized for polyolefin matrices. Such modifications often result in very significant enhancement of the composites' compatibility and improve their mechanical performance. Nevertheless, the drawback of this approach is the impossibility of the production of composites in a one-step process since the grafting of the modifier onto the polyolefin matrix has to be performed in a separate step. As a result, it is essential to investigate the storage stability of polymer matrices modified with isocyanates, since free isocyanate groups are very hygroscopic and may react with moisture leading to the generation of ureas. To the best of the authors' knowledge, this issue was not investigated.

Matrix-based strategies may also be introduced for other matrices, including those containing hydroxyl or carboxyl groups in structure, which can react with isocyanates without the incorporation of radical initiators. However, it is hard to control the extent of the modification process, and in the case of the application of diisocyanates, both groups may react with the polymer matrix leading to its cross-linking. Moreover, even if the extent of the reaction could be controlled, similarly to polyolefins, the storage stability of modified matrices should be investigated. Nevertheless, in the case of matrices containing functional groups in the macromolecular chain, it is easier to "upgrade" the modification process to the reactive processing approach.

Regarding filler-based approaches, it can be seen that, despite effective functionalization, methods described above show several drawbacks, including: long time of the process (even several days), very complex procedure (multiple unit processes included), and application of organic solvents (not in line with the Principles of Green Chemistry). It is also important to mention that these drawbacks are not related only to methods, which include the use of catalysts, but in general to modification procedures based on periodic batch processes. From a technological point of view, except for the issues mentioned above, the necessity of starting and ending the process for each batch also is very unfavorable, which often implicates post-process treatment of modified filler and cleaning of reactor or installation. As a result, such processes are more expensive, which has a direct impact on the cost of the modified filler, limiting its potential applications. Moreover, when modified fillers are aimed to be introduced into nonpolar matrices, it is essential to select the proper diisocyanate, which would provide the highest compatibility with the matrix, for example, polyolefins. According to the literature data, very promising results were noted for the application of pMDI or HDI, which was caused by the polymeric nature or structural similarities of modifiers to the matrix. 


\section{Reactive processing}

Due to the issues mentioned above, academic and industrial research groups are looking for a more efficient method for compatibilization of wood-polymer composites with isocyanates. Due to the high reactivity of the free isocyanate groups, it is very beneficial to perform in situ compatibilization during melt compounding. It would provide possibilities for the simultaneous generation of covalent bonds with functional groups of matrix and filler phases.

Such an approach was used in one of the first works related to in situ compatibilization of WPCs with isocyanates, published by Ashori and Nourbakhsh, and their research group (Ashori and Nourbakhsh 2009; Nourbakhsh et al. 2008). The authors applied polybutadiene isocyanate (PBNCO) as a coupling agent for WPCs based on the PP matrix, filled with aspen wood fibers, and depicted sugarcane bagasse. For comparison, a maleated polypropylene was also used as a compatibilizer. In terms of tensile strength, the incorporation of PBNCO provided a similar level of enhancement to MAPP. However, the best results were noted for the simultaneous use of both coupling agents. The tensile strength of PP/bagasse fiber composites exceeded $30 \mathrm{MPa}$, while it was around 24-25 MPa when only one compatibilizer was introduced. A similar phenomenon was observed for PP/aspen wood fiber composites. For impact strength, the synergic effect was even more substantial, because it tripled composites' strength, which exceeded $33 \mathrm{MPa}$, while for the sole use of PBNCO and MAPP, it was around 21 and $16 \mathrm{MPa}$, respectively. The observed enhancement of the mechanical performance of composites was ascribed by the authors to the strengthening of interfacial interactions due to the generation of covalent bonds and mutual complementing between two coupling agents.

Lately, Xie et al. (2020) prepared biocomposites based on the PBAT matrix filled with bamboo flour and compatibilized them with the different content of MDI (from 1 to 4 parts by weight). The authors noted significant enhancement of the mechanical properties of composites, which in detail is presented in Table 6. The presented results confirm the efficiency of in situ compatibilization. High yield of the reactions between free isocyanate groups and hydroxyl groups present on the surface of filler and in the backbone of the polymer matrix was confirmed by FTIR analysis. The presented spectra indicate the disappearance of signals associated with these groups and their replacement with peaks attributed to the presence of urethane groups.

Table 6 Changes in mechanical properties of PBAT/bamboo flour composites after compatibilization with MDI (Xie et al. 2020)

\begin{tabular}{|c|c|c|c|c|}
\hline \multirow{2}{*}{$\begin{array}{l}\text { MDI content, parts } \\
\text { by weight }\end{array}$} & \multicolumn{4}{|c|}{ Improvement in the mechanical properties (\%) } \\
\hline & Tensile strength & Tensile modulus & $\begin{array}{l}\text { Elongation at } \\
\text { break }\end{array}$ & Impact strength \\
\hline 1 & 74.7 & 47.2 & 191.1 & 446.3 \\
\hline 2 & 90.7 & 86.3 & 332.1 & 580.6 \\
\hline 3 & 84.0 & 74.2 & 305.4 & 664.2 \\
\hline 4 & 80.7 & 59.3 & 292.9 & 626.9 \\
\hline
\end{tabular}


Enhanced interfacial compatibility was also confirmed by the SEM analysis. Moreover, the generation of the urethane bonds between phases resulted in the shift of the onset of thermal decomposition by $30{ }^{\circ} \mathrm{C}$.

One step further in the development of the compatibilization methods based on reactive processing is the application of continuous processes, which would improve their ecological and economic aspects (Formela et al. 2017). One of the most efficient methods to improve matrix-filler interfacial interactions in biocomposites is in situ processing via reactive extrusion, which involves carrying out a designed chemical reaction between the components used. It is considered as fast, low-cost, and pro-ecologic alternative for "conventional" modification methods of natural fillers. Using extruders allows tailoring the energy and mixing conditions of the material in each barrel section, which affects the efficiency of mass and heat transfer. Furthermore, compared to "conventional" chemical reactors, the application of extruders allows the processing of viscous systems. A significant advantage of the extruders as reactors is the absence or reduced content of solvent as the reaction medium, which eliminates additional technological operations, such as the recovery of solvent or purification of the final product. Moreover, it significantly enhances the ecological aspect of the process. These are the main factors affecting the continuous development of reactive extrusion during laboratory and industrial modification. More comprehensively, the reactive extrusion of polymer blends and composites was described in previous works (Formela et al. 2017, 2018).

Petinakis et al. (2009) prepared PLA-based composites with wood flour compatibilized with MDI in twin screw extruder. The authors introduced $1 \mathrm{wt} \%$ of MDI, relatively to the content of filler, and investigated the impact of modification for various filler loadings. The authors noted relatively poor interfacial adhesion between PLA matrix and wood flour particles, which was ascribed to differences in polarity and lack of possibilities to generate covalent bonds between phases. Such assumptions were confirmed by SEM images, which showed significant voids at the interphase. Modification with MDI resulted in a more homogenous structure of fracture surface, which indicated the strengthening of interfacial interactions and the generation of covalent bonding. As a result, the mechanical performance of composites was enhanced, which is shown in Table 7. Modification of investigated composites with MDI was found to give superior results compared to those for the application of poly(ethylene-acrylic acid) copolymer.

Table 7 Changes in mechanical properties of PLA/wood flour composites after modification of filler with MDI (Petinakis et al. 2009)

\begin{tabular}{llll}
\hline $\begin{array}{l}\text { Filler } \\
\text { loading } \\
\text { (wt\%) }\end{array}$ & \multicolumn{2}{l}{ Enhancement of parameters $(\%)$} & \\
\cline { 2 - 4 } & Tensile strength & Elongation at break & Tensile modulus \\
\hline 0 & $\downarrow-1.77$ & $\uparrow 21.51$ & $\uparrow 8.71$ \\
5 & $\uparrow 3.03$ & $\uparrow 3.39$ & $\downarrow-2.63$ \\
10 & $\uparrow 7.00$ & $\uparrow 25.18$ & $\uparrow 0.97$ \\
20 & $\uparrow 6.56$ & $\uparrow 12.50$ & $\uparrow 0.54$ \\
30 & $\uparrow 14.36$ & $\uparrow 50.37$ & $\uparrow 5.14$ \\
40 & $\uparrow 9.03$ & $\uparrow 11.32$ & $\uparrow 19.86$ \\
\hline
\end{tabular}




\section{Conclusion}

The interest in wood-polymer composites is continuously growing due to current trends aimed at a reduction in the environmental impact of industry and the introduction of more bio-based materials or the ones produced from renewable raw materials. On the other hand, requirements set for composite materials are increasing. Therefore, it is essential to investigate the possibilities to enhance their performance. Obviously, having in mind all environmental and economic aspects, the review article clearly indicates that isocyanates may be efficiently applied as modifier and compatibilizer for wood-polymer composites. They have been repeatedly proven to provide similar or even higher levels of compatibility enhancement than commonly applied and valued anhydrides. Therefore, they should definitely be more often applied as modifiers for WPCs. However, a few issues have to be addressed.

First of all, as mentioned above, isocyanates as a group are considered toxic. Therefore, to develop sustainable, safe, and environmentally friendly processes of WPCs' modification, it is essential to determine their environmental impact. For solvent-based processes, the isocyanate content in generated sewage has to be investigated. However, even more critical should be the emission of volatiles during modification. Despite relatively low vapor pressure of the majority of isocyanates at room temperature, many of the investigated modification processes were conducted at elevated temperatures, at which vapor pressure may be dozens of times higher. Moreover, even at low concentrations, permanent exposition to isocyanate-based volatiles may cause harmful effects on human health. Therefore, it is essential to investigate the issue of volatile organic compounds as well as sewage emissions during modification processes and possibly introduce life cycle assessment analyses to determine the environmental impact of isocyanate modifications.

Secondly, in order to enhance the environmental aspect of modification processes, they have to be developed in a more efficient manner, according to the Principles of Green Chemistry. Therefore, periodic batch processes, often characterized by long duration, the necessity of starting and stopping the process, as well as high usage of organic solvents, should be continuously displaced by continuous processes. In contrast to batch processes, they are considered more environmentally friendly and more efficient. Among them, the most common is reactive extrusion, which could be applied to matrix-based and filler-based strategies, but most of all, to in situ compatibilization of WPCs during melt compounding in extruders. In the following years, more and more reports should be published regarding this issue.

Moreover, due to the enhancement of interfacial adhesion related to the incorporation of isocyanates, the lifetime of various products based on modified WPCs could be extended. Therefore, considering the long term, there will be no need to replace them with new products, for example, considering composite boards. At the same time, it is essential to look for the potential recycling methods of WPCs, especially modified ones, since the effects of chemical modifications of the fillers are often hardly reversible.

Further, it is crucial to keep an open mind and seek possibilities to incorporate isocyanate-modified polymers, fillers, and composites into novel applications. 
One of them is 3D printing, whose popularity is increasingly growing over the last years. WPCs, as well as modified fillers, may be applied to different 3D printing techniques, mostly in fused deposition modeling, very popular for thermoplastic polymers, and the most affordable, but also in stereolithography and selective layer sintering, where photocurable polymers and polymer powders may be used. On the other hand, except for such innovative applications as 3D printing, isocyanate-modified lignocellulosic fillers may be used to produce fiberboards, which is nowadays a common practice in the industry. Due to the high efficiency of isocyanates as modifiers for lignocellulosic fillers, they are applied as binders for lignocellulosic materials. Further research works related to the filler modification may provide new insights related, for example, to the use of new types of isocyanates or novel methods of modification. Acquired know-how may enable the application of various types of waste materials, whose relatively weak mechanical properties (compared to the conventional wood flour) are currently limiting their application range. Such an approach would create new routes for the recycling, for example, for various agricultural wastes, simultaneously increasing their utilization.

Acknowledgements This work was supported by the National Science Centre (NCN, Poland) in the frame of SONATINA 2 Project 2018/28/C/ST8/00187—Structure and properties of lignocellulosic fillers modified in situ during reactive extrusion.

\section{Compliance with ethical standards}

Conflict of interest All the authors declare that they have no conflict of interest.

Open Access This article is licensed under a Creative Commons Attribution 4.0 International License, which permits use, sharing, adaptation, distribution and reproduction in any medium or format, as long as you give appropriate credit to the original author(s) and the source, provide a link to the Creative Commons licence, and indicate if changes were made. The images or other third party material in this article are included in the article's Creative Commons licence, unless indicated otherwise in a credit line to the material. If material is not included in the article's Creative Commons licence and your intended use is not permitted by statutory regulation or exceeds the permitted use, you will need to obtain permission directly from the copyright holder. To view a copy of this licence, visit http://creativecommons.org/licen ses/by/4.0/.

\section{References}

Andrzejewski J, Szostak M, Barczewski M, Łuczak P (2019) Cork-wood hybrid filler system for polypropylene and poly(lactic acid) based injection molded composites. Structure evaluation and mechanical performance. Compos Part B Eng 163:655-668. https://doi.org/10.1016/j.composites b.2018.12.109

Arjmand F, Barmar M, Barikani M (2012) Isocyanate modification of wood fiber in enhancing the performance of its composites with high density polyethylene. Polym Renew Res 3(2):43-60. https://doi.org/10.1177/204124791200300202

Ashori A, Nourbakhsh A (2009) Polypropylene cellulose-based composites: the effect of bagasse reinforcement and polybutadiene isocyanate treatment on the mechanical properties. J Appl Polym Sci 111:1684-1689. https://doi.org/10.1002/app.29189 
Barczewski M, Andrzejewski J, Matykiewicz D, Krygier A, Kloziński A (2019) Influence of accelerated weathering on mechanical and thermomechanical properties of poly(lactic acid) composites with natural waste filler. Polimery 64(2):119-126. https://doi.org/10.14314/polimery.2019.2.5

Bettini SHP, Bonse BC, Melo EA, Muñoz PAR (2010) Effect of sawdust surface treatment and compatibilizer addition on mechanical behavior, morphology, and moisture uptake of polypropylene/ sawdust composites. Polym Eng Sci 50:978-985. https://doi.org/10.1002/pen.21617

Bledzki AK, Reihmane S, Gassan J (1998) Thermoplastics reinforced with wood fillers: a literature review. Polym Plast Technol 37:451-468. https://doi.org/10.1080/03602559808001373

Braun D, Schmitt MW (1998) Functionalization of poly(propylene) by isocyanate groups. Polym Bull 40(2-3):189-194. https://doi.org/10.1007/s002890050241

Chan CM, Vandi LJ, Pratt S, Halley P, Richardson D, Werker A, Laycock B (2017) Composites of wood and biodegradable thermoplastics: a review. Polym Rev 58(3):444-494. https://doi. org/10.1080/15583724.2017.1380039

Chauhan S, Karmarkar A, Aggarwal P (2009) Damping behavior of wood filled polypropylene composites. J Appl Polym Sci 114(4):2421-2426. https://doi.org/10.1002/app.30718

Da Róz AL, Curvelo AAS, Gandini A (2009) Preparation and characterization of cross-linked starch polyurethanes. Carbohydr Polym 77(3):526-529. https://doi.org/10.1016/j.carbpol.2009.01.035

European Bioplastics (2019) Bioplastics_facts and figures. https://docs.european-bioplastics.org/ publications/EUBP_Facts_and_figures.pdf. Accessed 01 Dec 2019

European Parliament and the Council (2008) Regulation (EC) No 1272/2008 of the European Parliament and of the Council of 16 December 2008 on classification, labelling and packaging of substances and mixtures, amending and repealing Directives 67/548/EEC and 1999/45/EC, and amending Regulation (EC) No 1907/2006. https://eur-lex.europa.eu/LexUriServ/LexUriServ.do? uri=OJ:L:2008:353:0001:1355:EN:PDF. Accessed 22 Nov 2019

Formela K, Hejna A, Piszczyk Ł, Saeb MR, Colom X (2016) Processing and structure-property relationships of natural rubber/wheat bran biocomposites. Cellulose 23:3157-3175. https://doi. org/10.1007/s10570-016-1020-0

Formela K, Hejna A, Haponiuk J, Tercjak A (2017) In situ processing of biocomposites via reactive extrusion. In: Ray D (ed) Biocomposites for high-performance applications. Woodhead Publishing, Cambridge, pp 195-246. https://doi.org/10.1016/b978-0-08-100793-8.00008-9

Formela K, Zedler Ł, Hejna A, Tercjak A (2018) Reactive extrusion of bio-based polymer blends and composites-current trends and future developments. Express Polym Lett 12:24-57. https://doi. org/10.3144/expresspolymlett.2018.4

Gallos A, Paës G, Allais F, Beaugrand J (2017) Lignocellulosic fibers: a critical review of the extrusion process for enhancement of the properties of natural fiber composites. RSC Adv 7(55):34638-34654. https://doi.org/10.1039/c7ra05240e

Geng Y, Li K, Simonsen J (2005) A combination of poly(diphenylmethane diisocyanate) and stearic anhydride as a novel compatibilizer for wood-polyethylene composites. J Adhes Sci Technol 19:987-1001. https://doi.org/10.1163/1568561054951013

George J, Bhagawan SS, Thomas S (1996) Thermogravimetric and dynamic mechanical thermal analysis of pineapple fibre reinforced polyethylene composites. J Therm Anal 47(4):1121-1140. https://doi.org/10.1007/bf01979452

George J, Bhagawan SS, Thomas S (1997) Improved interactions in chemically modified pineapple leaf fiber reinforced polyethylene composites. Compos Interface 5(3):201-223. https://doi. org/10.1163/156855498x00153

George J, Sreekala MS, Thomas S (2001) A review on interface modification and characterization of natural fiber reinforced plastic composites. Polym Eng Sci 41(9):1471-1485. https://doi. org/10.1002/pen.10846

Gironès J, Pimenta MTB, Vilaseca F, de Carvalho AJF, Mutjé P, Curvelo AAS (2007) Blocked isocyanates as coupling agents for cellulose-based composites. Carbohydr Polym 68(3):537-543. https://doi.org/10.1016/j.carbpol.2006.10.020

Girouard NM, Xu S, Schueneman GT, Shofner ML, Meredith JC (2016) Site-selective modification of cellulose nanocrystals with isophorone diisocyanate and formation of polyurethane-CNC composites. ACS Appl Mater Inter 8(2):1458-1467. https://doi.org/10.1021/acsami.5b10723

Gómez-Fernández S, Ugarte L, Calvo-Correas T, Pena-Rodriguez C, Corcuera MA, Eceiza A (2017) Properties of flexible polyurethane foams containing isocyanate functionalized kraft lignin. Ind Crop Prod 100:51-64. https://doi.org/10.1016/j.indcrop.2017.02.005 
Guo CG, Wang QW (2008) Influence of $m$-isopropenyl- $\alpha, \alpha$-dimethylbenzyl isocyanate grafted polypropylene on the interfacial interaction of wood-flour/polypropylene composites. J Appl Polym Sci 109(5):3080-3086. https://doi.org/10.1002/app.27800

Guo C, Li L, Wang Q (2011) Investigation on the compatibilizing effect of $m$-isopropenyl- $\alpha$, $\alpha$-dimethylbenzyl isocyanate grafted polypropylene on polypropylene and wood flour composites. Wood Sci Technol 46(1-3):257-270. https://doi.org/10.1007/s00226-011-0409-z

Guo C, Ma L, Sun C, Li L (2013) Influence of high loaded wood flour and coupling agent ( $m$-TMI$g$-PP) content on properties of wood flour/polypropylene. J Adhes Sci Technol 27(8):912-923. https://doi.org/10.1080/01694243.2012.727163

Guo C, Li L, Li H (2019) Evaluation of interfacial compatibility in wood flour/polypropylene composites by grafting isocyanate silane coupling agent on polypropylene. J Adhes Sci Technol 33(5):468-478. https://doi.org/10.1080/01694243.2018.1541635

Gwon JG, Cho HJ, Lee D, Choi DH, Lee S, Wu Q, Lee SY (2018) Physicochemical and mechanical properties of polypropylene-cellulose nanocrystal nanocomposites: effects of manufacturing process and chemical grafting. BioResources 13(1):1619-1636. https://doi.org/10.15376/biores.13.1.1619-1636

Hejna A, Kosmela P (2020) Insights into compatibilization of poly( $\varepsilon$-caprolactone)-based biocomposites with diisocyanates as modifiers of cellulose fillers. Mindanao J Sci Technol 18(1):221-241

Hejna A, Lenża J, Formela K, Korol J (2019) Studies on the combined impact of starch source and multiple processing on selected properties of thermoplastic starch/ethylene-vinyl acetate blends. J Polym Environ 27(5):1112-1126. https://doi.org/10.1007/s10924-019-01406-1

Hosseinpourpia R, Echart A, Adamopoulos S, Gabilondo N, Eceiza A (2018) Modification of pea starch and dextrin polymers with isocyanate functional groups. Polymers 10(9):939-951. https://doi. org/10.3390/polym10090939

Johns WE (1982) Isocyanates as wood binders-a review. J Adhes 15(1):59-67. https://doi. org/10.1080/00218468208073216

Joly C, Gauthier R, Escoubes M (1996) Partial masking of cellulosic fiber hydrophilicity for composite applications Water sorption by chemically modified fibers. J Appl Polym Sci 61(1):57-69. https:// doi.org/10.1002/(sici)1097-4628(19960705)61:1\%3c57:aid-app7\%3e3.0.co;2-t

Joseph K, Thomas S, Pavithran C (1995) Effect of ageing on the physical and mechanical properties of sisal-fiber-reinforced polyethylene composites. Compos Sci Technol 53(1):99-110. https://doi. org/10.1016/0266-3538(94)00074-3

Joseph K, Thomas S, Pavithran C (1996) Effect of chemical treatment on the tensile properties of short sisal fibre-reinforced polyethylene composites. Polymer 37(23):5139-5149. https://doi. org/10.1016/0032-3861(96)00144-9

Jun CL (2000) Reactive blending of biodegradable polymers: PLA and starch. J Polym Environ 8:33-37. https://doi.org/10.1023/A:1010172112118

Kabir MM, Wang H, Lau KT, Cardona F (2012) Chemical treatments on plant-based natural fibre reinforced polymer composites: an overview. Compos Part B Eng 43(7):2883-2892. https://doi. org/10.1016/j.compositesb.2012.04.053

Kalia S, Kaith BS, Kaur I (2009) Pretreatments of natural fibers and their application as reinforcing material in polymer composites—a review. Polym Eng Sci 49(7):1253-1272. https://doi.org/10.1002/ pen. 21328

Karmarkar A, Chauhan SS, Modak JM, Chanda M (2007) Mechanical properties of wood-fiber reinforced polypropylene composites: effect of a novel compatibilizer with isocyanate functional group. Compos Part A Appl Sci 38(2):227-233. https://doi.org/10.1016/j.compositesa.2006.05.005

Kweon DK, Cha DS, Park HJ, Lim ST (2000) Starch- $g$-polycaprolactone copolymerization using diisocyanate intermediates and thermal characteristics of the copolymers. J Appl Polym Sci 78(5):986-993. https://doi.org/10.1002/1097-4628(20001031)78:5\%3c986:aid-app70\%3e3.0.co;2-t

Labet M, Thielemans W, Dufresne A (2007) Polymer grafting onto starch nanocrystals. Biomacromolecules 8(9):2916-2927. https://doi.org/10.1021/bm700468f

Lai SM, Yeh FC, Wang Y, Chan HC, Shen HF (2003) Comparative study of maleated polyolefins as compatibilizers for polyethylene/wood flour composites. J Appl Polym Sci 87:487-496. https://doi. org/10.1002/app.11419

Li Q, Matuana LM (2003) Effectiveness of maleated and acrylic acid-functionalized polyolefin coupling agents for HDPE-wood-flour composites. J Thermoplast Compos Mater 16:551-564. https://doi. org/10.1177/089270503033340

Liew FK, Hamdan S, Rahman MR, Mahmood MR, Lai JCH (2018) The effects of nanoclay and tin(IV) oxide nanopowder on morphological, thermo-mechanical properties of hexamethylene diisocyanate 
treated jute/bamboo/polyethylene hybrid composites. J Vinyl Addit Technol 24:358-366. https://doi. org/10.1002/vnl.21600

Liu R, Peng Y, Cao J, Chen Y (2014) Comparison on properties of lignocellulosic flour/polymer composites by using wood, cellulose, and lignin flours as fillers. Compos Sci Technol 103:1-7. https://doi. org/10.1016/j.compscitech.2014.08.005

Maldas D, Kokta BV, Raj RG, Daneault C (1988) Improvement of the mechanical properties of sawdust wood fibre-polystyrene composites by chemical treatment. Polymer 29(7):1255-1265. https://doi. org/10.1016/0032-3861(88)90053-5

Maldas D, Kokta BV, Daneault C (1989) Thermoplastic composites of polystyrene: effect of different wood species on mechanical properties. J Appl Polym Sci 38(3):413-439. https://doi.org/10.1002/ app.1989.070380303

Mani R, Tang J, Bhattacharya M (1998) Synthesis and characterization of starch-graft-polycaprolactone as compatibilizer for starch/polycaprolactone blends. Macromol Rapid Commun 19(6):283-286. https://doi.org/10.1002/(sici)1521-3927(19980601)19:6\%3c283:aid-marc283\%3e3.0.co;2-c

Market Research Report (2018) Wood plastic composite market analysis report by type (polyethylene, polypropylene, polyvinylchloride), by application (automotive, construction, industrial \& consumer goods), and segment forecasts, pp 2018-2025. https://www.grandviewresearch.com/industry-analy sis/wood-plastic-composites-market. Accessed 01 Dec 2019

Meimoun J, Wiatz V, Saint-Loup R, Parcq J, Favrelle A, Bonnet F, Zinck P (2017) Modification of starch by graft copolymerization. Starch 70(1-2):1600351. https://doi.org/10.1002/star.201600351

Mohit H, Arul Mozhi Selvan V (2018) A comprehensive review on surface modification, structure interface and bonding mechanism of plant cellulose fiber reinforced polymer based composites. Compos Interface 25(5-7):629-667. https://doi.org/10.1080/09276440.2018.1444832

Morelli CL, Belgacem N, Bretas RES, Bras J (2016) Melt extruded nanocomposites of polybutylene adipate-co-terephthalate (PBAT) with phenylbutyl isocyanate modified cellulose nanocrystals. J Appl Polym Sci 133(34):43678. https://doi.org/10.1002/app.43678

Musk AW, Peters JM, Wegman DH (1988) Isocyanates and respiratory disease: current status. Am J Ind Med 13:331-349. https://doi.org/10.1002/ajim.4700130304

Nachtigall S, Cerveira GS, Rosa SML (2007) New polymeric-coupling agent for polypropylene/woodflour composites. Polym Test 26:619-628. https://doi.org/10.1016/j.polymertesting.2007.03.007

Nair KCM, Thomas S (2003) Effect of interface modification on the mechanical properties of polystyrene-sisal fiber composites. Polym Compos 24(3):332-343. https://doi.org/10.1002/pc.10033

NFPA (2017) NFPA 704: standard system for the identification of the hazards of materials for emergency response. https://www.nfpa.org/codes-and-standards/all-codes-and-standards/list-of-codes-andstandards/detail?code $=704$. Accessed 22 Nov 2019

Ni J, Frazier CE (1998) ${ }^{15} \mathrm{~N}$ CP/MAS NMR study of the isocyanate/wood adhesive bondline. Effects of structural isomerism. J Adhes 66(1-4):89-116. https://doi.org/10.1080/00218469808009961

Nourbakhsh A, Kokta BV, Ashori A, Jahan-Latibari A (2008) Effect of a novel coupling agent, polybutadiene isocyanate, on mechanical properties of wood-fiber polypropylene composites. J Reinf Plast Compos 27:1679-1687. https://doi.org/10.1177/0731684407087377

Ohkita T, Lee SH (2004) Effect of aliphatic isocyanates (HDI and LDI) as coupling agents on the properties of eco-composites from biodegradable polymers and corn starch. J Adhes Sci Technol 18(8):905-924. https://doi.org/10.1163/156856104840516

Paul A, Joseph K, Thomas S (1997) Effect of surface treatments on the electrical properties of low-density polyethylene composites reinforced with short sisal fibers. Compos Sci Technol 57(1):67-79. https://doi.org/10.1016/s0266-3538(96)00109-1

Petinakis E, Yu L, Edward G, Dean K, Liu H, Scully AD (2009) Effect of matrix-particle interfacial adhesion on the mechanical properties of poly(lactic acid)/wood-flour micro-composites. J Polym Environ 17(2):83-94. https://doi.org/10.1007/s10924-009-0124-0

Pickering KL, Ji C (2004) The effect of poly[methylene(polyphenyl isocyanate)] and maleated polypropylene coupling agents on New Zealand radiata pine fiber-polypropylene composites. J Reinf Plast Compos 23:2011-2024. https://doi.org/10.1177/0731684404041139

Pracella M, Chionna D, Anguillesi I, Kulinski Z, Piorkowska E (2006) Functionalization, compatibilization and properties of polypropylene composites with hemp fibres. Compos Sci Technol 66:22182230. https://doi.org/10.1016/j.compscitech.2005.12.006

Qiu W, Zhang F, Endo T, Hirotsu T (2005) Isocyanate as a compatibilizing agent on the properties of highly crystalline cellulose/polypropylene composites. J Mater Sci 40(14):3607-3614. https://doi. org/10.1007/s10853-005-0790-9 
Raj RG, Kokta BV, Maldas D, Daneault C (1989) Use of wood fibers in thermoplastics. VII. The effect of coupling agents in polyethylene-wood fiber composites. J Appl Polym Sci 37(4):1089-1103. https:// doi.org/10.1002/app.1989.070370420

Raj RG, Kokta BV, Daneault C (1990) The use of isocyanate as a bonding agent to improve the mechanical properties of polyethylene-wood fiber composites. Int J Polym Mater 14(3-4):223-234. https:// doi.org/10.1080/00914039008031515

Rensch HP, Riedl B (1992) Characterization of chemically modified chemithermomechanical pulp by thermal analysis. Thermochim Acta 210:171-183. https://doi.org/10.1016/0040-6031(92)80287-7

Thielemans W, Belgacem MN, Dufresne A (2006) Starch nanocrystals with large chain surface modifications. Langmuir 22(10):4804-4810. https://doi.org/10.1021/la053394m

Valodkar M, Thakore S (2010) Isocyanate crosslinked reactive starch nanoparticles for thermoresponsive conducting applications. Carbohydr Res 345:2354-2360. https://doi.org/10.1016/j.carre s.2010.08.008

Wang K, Dong Y, Yan Y, Zhang W, Qi C, Han C, Li J, Zhang S (2017) Highly hydrophobic and selfcleaning bulk wood prepared by grafting long-chain alkyl onto wood cell walls. Wood Sci Technol 51(2):395-411. https://doi.org/10.1007/s00226-016-0862-9

Xie X, Zhang C, Weng Y, Diao X, Song X (2020) Effect of diisocyanates as compatibilizer on the properties of BF/PBAT composites by in situ reactive compatibilization, crosslinking and chain extension. Materials 13(3):806. https://doi.org/10.3390/ma13030806

Zdrahala RJ, Zdrahala IJ (1999) Biomedical applications of polyurethanes: a review of past promises, present realities, and a vibrant future. J Biomater Appl 14:67-90. https://doi.org/10.1177/08853 2829901400104

Zhang C, Li K, Simonsen J (2004) Improvement of interfacial adhesion between wood and polypropylene in wood-polypropylene composites. J Adhes Sci Technol 18:1603-1612. https://doi. org/10.1163/1568561042411330

Zhang Y, Li H, Li X, Gibril ME, Yu M (2014) Chemical modification of cellulose by in situ reactive extrusion in ionic liquid. Carbohydr Polym 99:126-131. https://doi.org/10.1016/j.carbp ol.2013.07.084

Zhao S, Song J, Wang S (2008) Surface characterization of a series of cured polyurethane adhesives by inverse gas chromatography and adhesion strength testing of plywood. Wood Sci Technol 43(12):105-112. https://doi.org/10.1007/s00226-008-0229-y

Publisher's Note Springer Nature remains neutral with regard to jurisdictional claims in published maps and institutional affiliations. 